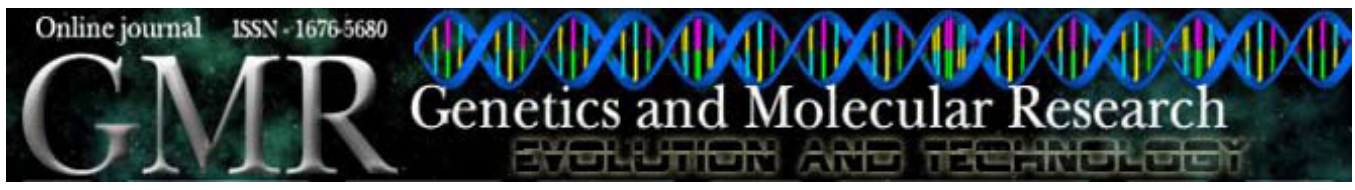

\title{
M13-microsatellite PCR and rDNA sequence markers for identification of Trichoderma (Hypocreaceae) species in Saudi Arabian soil
}

\author{
K.A. Abd-Elsalam ${ }^{1,2}$, I. Almohimeed ${ }^{1}$, M.A. Moslem ${ }^{1}$ and A.H. Bahkali ${ }^{1}$ \\ ${ }^{1}$ Botany and Microbiology Department, College of Science, \\ King Saud University, Riyadh, Saudi Arabia \\ ${ }^{2}$ Abdul Rahman Al-Jeraisy DNA Research Chair, College of Science, \\ King Saud University, Riyadh, Saudi Arabia \\ Corresponding author: K.A. Abd-Elsalam \\ E-mail: kamel200@ksu.edu.sa
}

Genet. Mol. Res. 9 (4): 2016-2024 (2010)

Received May 10, 2010

Accepted June 21, 2010

Published October 13, 2010

DOI 10.4238/vol9-4gmr908

\begin{abstract}
Seven fungal isolates were identified as pan-global Hypocrea/Trichoderma species, from section Trichoderma, on the basis of their morphology. These species were H. lixii/T. harzianum and $H$. orientalis/T. longibrachiatum. PCR-based markers with primer M13 (core sequence of phage M13) and internal-transcribed spacer sequences of ribosomal DNA were used to confirm the identity of the two Trichoderma species. Sequence identification was performed using the TrichOKEY version 2.0 barcode program and the multilocus similarity search database TrichoBLAST. Sequences from the ribosomal DNA internal-transcribed spacer regions showed limited variation among the Trichoderma species. This analysis divided the isolates into two main groups. Grouping the isolates based on cluster analysis of their DNA
\end{abstract}


profiles matched the grouping based on morphological taxonomy. Molecular data obtained from analyses of gene sequences are essential to distinguish phonetically cryptic species in this group and to establish phylogenetic relationships.

Key words: Trichoderma; Phytopathogenic fungi; PCR; Biological control

\section{INTRODUCTION}

Species in the filamentous fungal genus Trichoderma are of great economic importance as sources of enzymes and antibiotics, plant growth promoters, decomposers of xenobiotics, and most importantly, as commercial biofungicides (Sieburg, 1990; Howell, 2003; Sariah et al., 2005). Thus, they are potential candidates for biocontrol applications. Species of the filamentous fungus Hypocrea/Trichoderma are used in agriculture as biocontrol agents due to their mycoparasitic action against plant pathogenic fungi and their beneficial effects on plant growth and root development. The taxonomy of Hypocreal Trichoderma is rather difficult and complex due to the plasticity of characters if classical approaches, based on morphological criteria, are applied. Morphological analysis is highly prone to error, and consequently roughly $50 \%$ of the Trichoderma spp deposited in culture collections under names obtained by morphological analysis alone are wrong (Druzhinina and Kubicek, 2005). Samuels and colleagues (2002), advocating the morphologically and physiologically based methods, proposed an interactive key for strain identification in Trichoderma, which, besides relying on subtle differences in morphology (http://nt.ars-grin.gov/taxadescriptions/keys/TrichodermaIndex.cfm), makes use of differences in growth rates on potato dextrose agar (PDA) and synthetic nutrient agar at $15,20,25,30$ and $35^{\circ} \mathrm{C}$ (Chaverri et al., 2003). This method is inexpensive, but is timeconsuming and requires a sufficient number of repetitions $(\mathrm{N}>5)$ for each sample to be reliable, thus becoming laborious with more than 50 samples being considered as the lowest limit for any ecological investigation.

The use of molecular phylogenetic markers has refined Hypocrea/Trichoderma taxonomy significantly, and phylogenetic analysis of the large number of Hypocrea/Trichoder$m a$ spp is still a field of active ongoing research (Druzhinina et al., 2005). There is limited information on the population dynamics of Trichoderma, particularly its survivability and proliferation in relation to soil type, soil depth and cropping history in Peninsular Malaysia (Sariah et al., 2005). However, the search for new phylogenetic markers is strongly recommended. The species identification tools will help to answer the question whether particular taxa are to be preferred on particular hosts or plants. The objectives of this research were to characterize isolates of Trichoderma collected from protected areas in Saudi Arabia using microsatellite-primed polymerase chain reaction (MP-PCR) and ribosomal DNA (rDNA) sequence analysis and to combine these results with morphological characteristics for classification. Isolates were identified at the species level by the oligonucleotide BarCode for Hypocrea/Trichoderma (TrichOKEY), sequence similarity analysis (TrichoBLAST) and phylogenetic inferences. 


\section{MATERIAL AND METHODS}

\section{Fungal isolates and growth conditions}

Trichoderma spp was originally isolated from soil collected from protected areas (Rawdet Khuraim) in Saudi Arabia. They were cultured on PDA (Difco, Detroit, MI, USA) or rose bengal agar at $28^{\circ} \mathrm{C}$ for five days. After an incubation period, colonies were purified and determined to be Trichoderma spp according to Rifai (1969) and confirmed using Trichoderma morphological key. Single-spore isolates of seven Trichoderma isolates were cultured in Erlenmeyer flasks $(250 \mathrm{~mL})$ containing $50 \mathrm{~mL}$ potato dextrose broth at $25^{\circ} \mathrm{C}$ for seven days. Mycelia were harvested by filtration through two layers of cheesecloth. Samples were frozen in liquid nitrogen and ground to fine powder using a mortar and pestle.

\section{DNA extraction}

A modification of the traditional sodium dodecyl sulfate (SDS) extraction procedure was adopted. Fresh fungal mats $(100 \mathrm{mg})$ were homogenized in $400 \mu \mathrm{L}$ sterile salt homogenizing buffer ( $200 \mathrm{mM}$ Tris- $\mathrm{HCl}, \mathrm{pH} 8.5,250 \mathrm{mM} \mathrm{NaCl}, 25 \mathrm{mM}$ EDTA, 0.5\% SDS). Next, $6 \mu \mathrm{L} 20 \mathrm{mg} / \mathrm{mL}$ RNase A was added and mixed well. The samples were incubated at $65^{\circ} \mathrm{C}$ for $10 \mathrm{~min}$, after which $130 \mu \mathrm{L} 3 \mathrm{M}$ sodium acetate, $\mathrm{pH} 5.2$, was added to each sample. Samples were vortexed for $30 \mathrm{~s}$ at maximum speed, and incubated at $-20^{\circ} \mathrm{C}$ for $10 \mathrm{~min}$. The lysate was centrifuged at $13,000 \mathrm{rpm}$ at $4^{\circ} \mathrm{C}$ for $15 \mathrm{~min}$, and the supernatant was transferred to fresh tubes. An equal volume of isopropanol was added to each sample, and after mixing well, and samples were incubated at $-20^{\circ} \mathrm{C}$ for $10 \mathrm{~min}$. Samples were then centrifuged for $20 \mathrm{~min}$ at $4^{\circ} \mathrm{C}$, at $6000 \mathrm{rpm}$. The DNA pellets were washed twice using $700 \mu \mathrm{L}$ washing solution (100 and $70 \%$ ethanol, respectively). The DNA pellets were subsequently air dried in an oven at $40^{\circ} \mathrm{C}$ for at least $10 \mathrm{~min}$. The resultant DNA pellet was then resuspended in $100 \mu \mathrm{L} 1 \mathrm{X}$ TE (10 mM Tris-HCl, $1 \mathrm{mM}$ EDTA) buffer, $\mathrm{pH}$ 8.0 (Abd-Elsalam et al., 2007).

\section{DNA quantification and gel documentation}

Seven microliters of the isolated DNA and $3 \mu \mathrm{L}$ of $10 \mathrm{X}$ loading dye were loaded in a lane of $1.5 \%(\mathrm{w} / \mathrm{v})$ agarose gel containing $0.05 \mu \mathrm{g} / \mathrm{mL}$ ethidium bromide, to check the quality of the DNA. For quantitative measurements, a charge-coupled device camera imaging system and UVIsoft analysis (Gel Documentation and Analysis Systems, Uvitec, Cambridge, UK) were used to capture the image and to calculate the band intensities.

\section{Amplification of microsatellite-primed PCR}

Amplifications were performed using $1 \mu \mathrm{L}$ DNA and the core sequence of the microsatellite M-13, 5'-GAGGGTGGCGGTTCT-3', was used as a primer according to Asran-Amal et al. (2005). The cycling parameters were: pre-denaturation at $93^{\circ} \mathrm{C}$ for 3 
min, followed by 45 cycles of $93^{\circ} \mathrm{C}$ denaturation for $1 \mathrm{~min}, 55^{\circ} \mathrm{C}$ annealing for $1 \mathrm{~min}$, $72^{\circ} \mathrm{C}$ extension for $1 \mathrm{~min}$, and a $72^{\circ} \mathrm{C}$ final extension for $10 \mathrm{~min}$. Amplification products were separated on $1.5 \%$ agarose gel in TAE (Tris-acetic acid-EDTA) buffer and stained with $0.1 \%$ ethidium bromide. For quantitative measurements, a charge-coupled device camera imaging system and UVIsoft analysis (Gel Documentation and Analysis Systems, Uvitec, Cambridge, UK) were used to capture the image and to calculate the band intensities.

\section{ITS-PCR conditions}

Polymerase chain reaction was conducted in a $50-\mu \mathrm{L}$ reaction volume. One microliter DNA (1 ng quantified with a spectrophotometer) was added to a $49-\mu \mathrm{L}$ master reaction mixture containing $5 \mu \mathrm{L}$ 10X PCR buffer, $36.6 \mu \mathrm{L}$ sterile distilled $\mathrm{H}_{2} \mathrm{O}, 1 \mu \mathrm{L} 10 \mathrm{mM} \mathrm{MgCl}, 2 \mu \mathrm{L} 2$ $\mathrm{mM}$ dNTPs, $2 \mu \mathrm{L} 10 \mathrm{pmol}$ ITS1 primer, $2 \mu \mathrm{L} 10$ pmol ITS4 primer, and $0.4 \mu \mathrm{L}$ Taq polymerase (ABgene). All reactions were overlaid with sterile mineral oil prior to thermal cycling. The sequences of the internal-transcribed spacer 1 and 4 (ITS1 and ITS4) primers were 5'-TCCG TAGGTGAACCTGCGG-3' and 5'-TCCTCCGCTTATTGATATGC-3' (White et al., 1990), respectively. Thermal cycling parameters were an initial denaturation at $96^{\circ} \mathrm{C}$ for $2 \mathrm{~min}$, followed by 35 cycles consisting of denaturation at $96^{\circ} \mathrm{C}$ for $1 \mathrm{~min}$, annealing at $55^{\circ} \mathrm{C}$ for $1 \mathrm{~min}$, and extension at $72^{\circ} \mathrm{C}$ for $2 \mathrm{~min}$. A final extension at $72^{\circ} \mathrm{C}$ for $10 \mathrm{~min}$ was followed. DNA $(50$ $\mu \mathrm{L}$ ) was directly prepared from PCR products by purifying it with a commercial kit (QIAquick ${ }^{\circledR}$ PCR Purification Kit, Qiagen).

\section{Cloning and sequencing of ITS markers}

For cloning of the ribosomal DNA regions, the purified amplification product was ligated into the EcoRV site of the pGM-T vector system (Promega) according to manufacturer instructions. The boiling method (Sambrook et al., 2001) was used to isolate plasmid DNA from the bacterial host. Amplicon purification and sequencing was also done as previously described in detail (Kullnig-Gradinger et al., 2002).

\section{In silico tools and sequence alignment}

The Trichoderma isolates were identified by comparison of the ribosomal intergenic spacer sequences between 18S and 28S rRNA, including ITS1-5.8 SrRNA-ITS2 regions, in databanks (NCBI http://www.ncbi.nlm.nih.gov/BLAST/ and ISTH-TrichOkey at http://www.isth. info/tools/molkey/index.php). Computer-aided alignment of the ITS1 region sequence was performed using the computer software CLC Sequence Viewer 6.0.1 (CLC bio, USA). The alignment was then optimized manually. Single gaps were treated as a fifth nucleotide (A, C, G, T, and gaps). All gap positions within the alignment exceeding a single base in length were replaced by question marks. Sequence insertions without homology to any of the other sequences were deleted in the alignment and a single base was left over causing a minimal gap. In this way, gaps of all sizes were equally weighted, corresponding to a hypothetical single evolutionary event. Therefore, alignment adjustments were finally made manually in order to remove artificial gaps. The aligned sequences were visually inspected and adjustments made to improve the alignment. 


\section{RESULTS}

\section{Culture characterization of Trichoderma isolates}

T. harzianum growing on Sabroud-dextrose agar, malt yeast agar, and PDA appeared as white colonies with appressed mycelia, but without clear zonation on PDA. While mycelia were initially whitish, aerial on the surface of the PDA medium, zonation was evident in few cases (Figure 1).

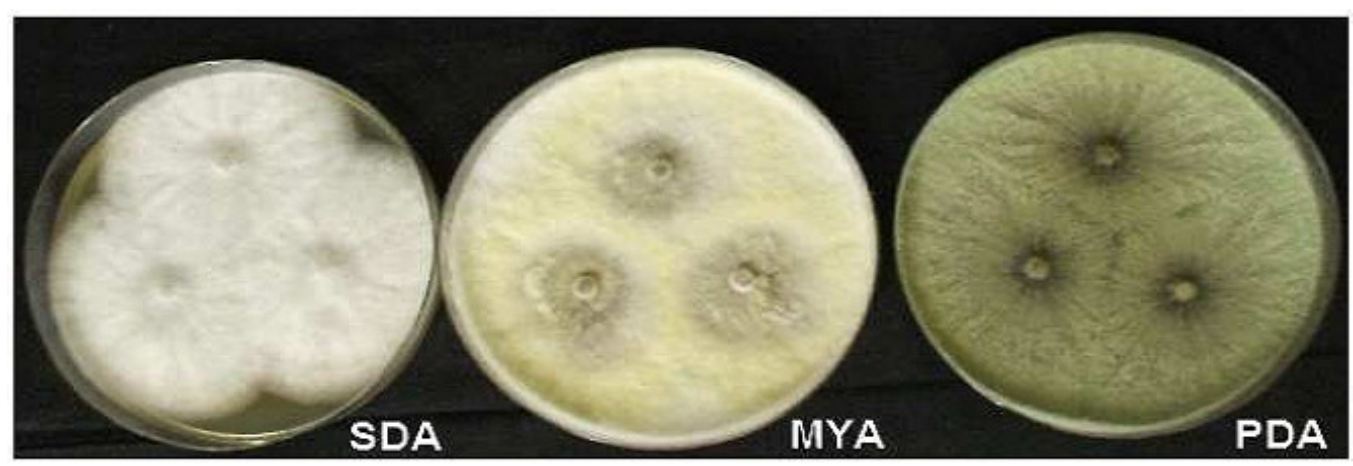

Figure 1. Cultural characteristics of Trichoderma harzianum colonies on Sabroud-dextrose agar (SDA) bright white appressed mycelium, becoming yellowish on malt yeast agar (MYA), and aerial on the surface of potato dextrose agar medium (PDA).

\section{Molecular identification of Trichoderma isolates}

Molecular approaches including MP-PCR fingerprinting and ITS sequences of ribosomal DNA were used to study the genetic relatedness of two Trichoderma species. Numerical analysis of microsatellite-primed profiles revealed two clusters at $62 \%$ genetic homology. Isolates within these clusters were considered to be genetically related. The first cluster consisted of three isolates of T. harzianum. In this cluster, there was a good correlation between subclustering and geographic origin of the isolates tested. These isolates showed $92 \%$ homology, and the highest homology $(100 \%)$ was found between isolates 1 and 3 . The second cluster was composed of all T. longibrachiatum isolates (Figure 2). On amplification using ITS primers, the isolated DNA showed high intensity bands. The PCR products obtained from the rDNA amplification were approximately 550-700 bp in different Trichoderma species (Figure 3).The amplified DNA was sequenced and aligned against ex-type strain sequences from TrichOKEY/ GenBank and established Trichoderma taxonomy. A multiple sequence alignment was carried out including the ITS1 region and gaps. There were quite a number of gaps introduced in the multiple sequence alignment within the ITS1 region that were closely related, indicating a similar sequence (Figure 4). The dendrogram obtained by the UPGMA clustering method revealed the genetic relationship of two different species of Trichoderma from a total of seven Trichoderma isolates tested in this study (Figure 5). Three isolates were positively identified as T. harzianum and four isolates of $T$. longibrachiatum clearly formed a defining phylogenetic analysis. 


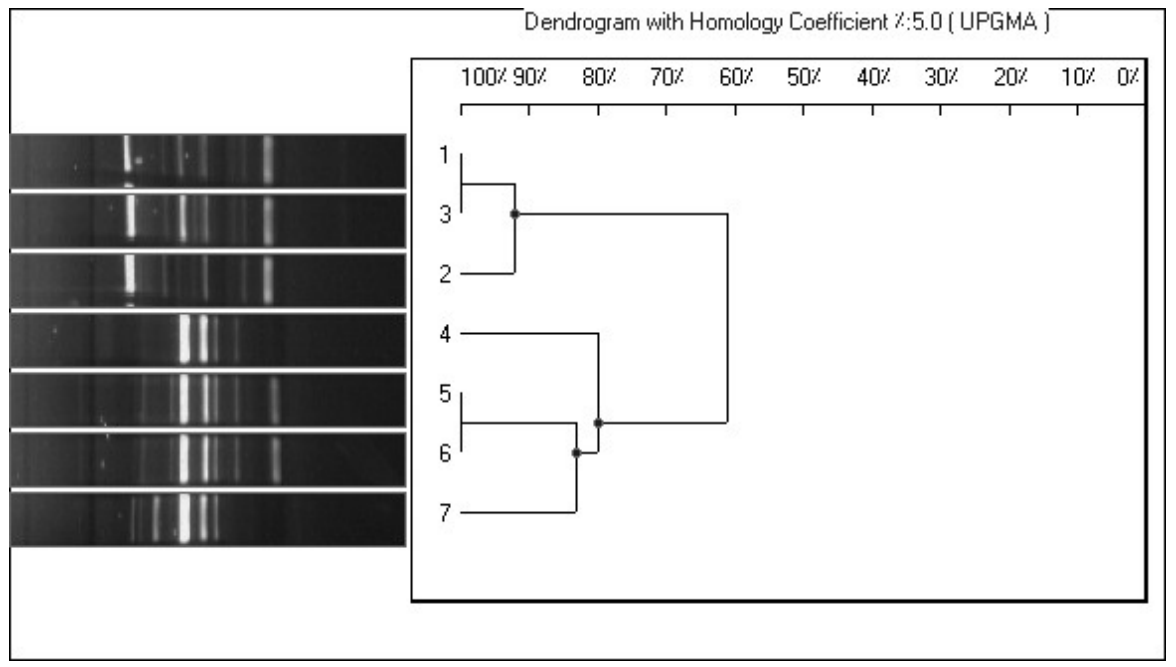

Figure 2. Cluster analysis (unweighted pair-group method using arithmetic averages, UPGMA) of Trichoderma isolates based on DNA fingerprinting using microsatellite-primed PCR. Lanes 1-3 = T. harzianum; lanes 4-7 $=T$. longibrachiatum.

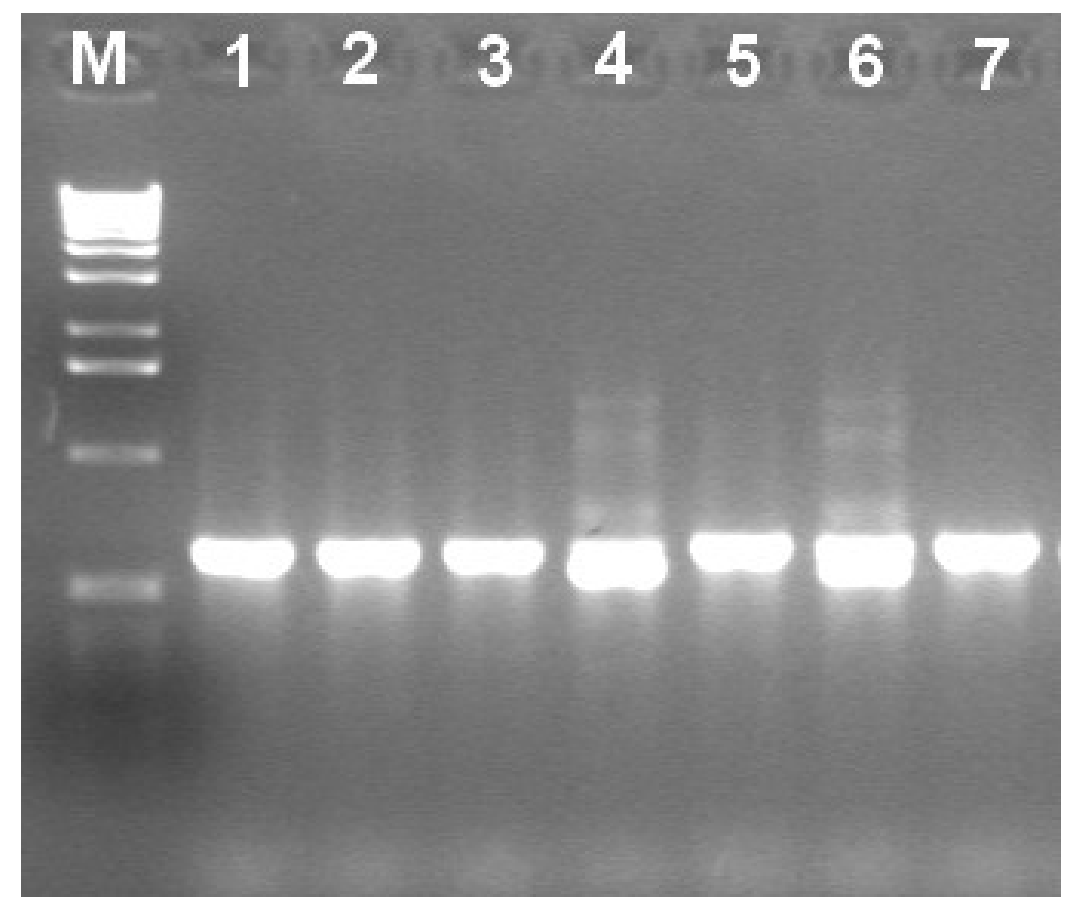

Figure 3. Full-internal-transcribed spacer (ITS) PCR products amplified from different Trichoderma species isolates, with ITS1/ITS4 primers. Lanes 1-3 $=$ T. harzianum; lanes 4-7 = T. longibrachiatum. 


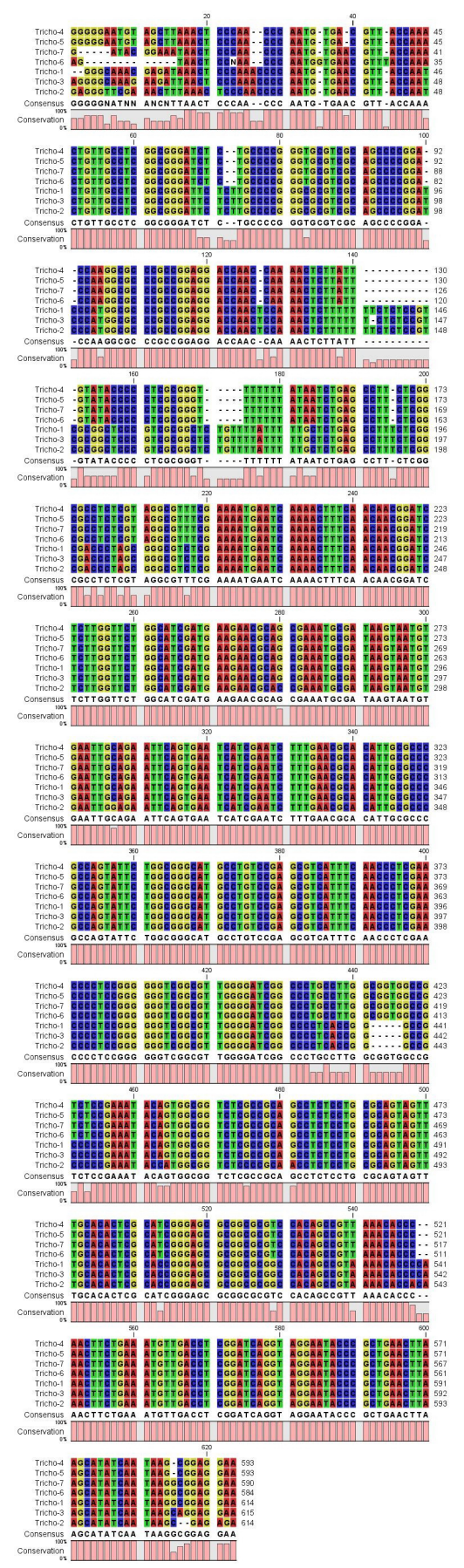

Figure 4. DNA sequence alignment of the internal-transcribed spacer (ITS) region (covering ITS1 region, 5.8S gene and ITS2 region) amplified from seven Trichoderma species isolates. 


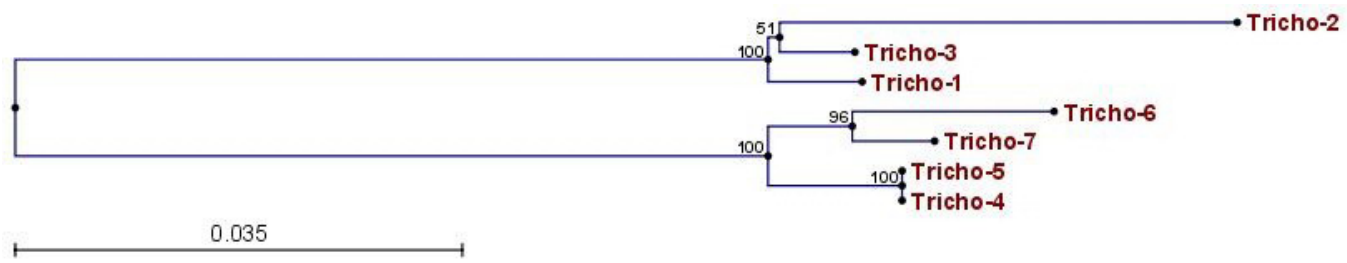

Figure 5. Phylogenetic relationships among species of Trichoderma inferred from nucleotide sequences of the internal-transcribed spacer and 5.8S RNA gene. The scale bar represents genetic distance.

\section{DISCUSSION}

DNA-based molecular methods have become routinely used tools in clinical microbiological laboratories for species identification and epidemiological investigations of emerging filamentous fungal pathogens (Nagy et al., 2004). In the current research, we describe the main results of a study on the occurrence and biodiversity of Trichoderma spp from undisturbed soil ecosystems in some protected areas in Saudi Arabia. Some heterogeneity in growth rate and colony morphology was observed among isolates of $T$. harzianum. Two species were identified, including T. harzianum and T. longibrachiatum. Morphological and culture data did not distinguish $T$. harzianum species isolates (Chaverri et al., 2003). Seven isolates were identified at the species level by sequence analysis of their microsatellite-primed PCR based on the phage M13 core sequence or by ITS 1 and 2 regions of the rDNA cluster. Based on the molecular marker techniques used in the current study, the genera examined were divided into two main clusters. The major cluster included four T. longibrachiatum isolates belonging to the genus Trichoder$m a$, whereas the second minor cluster included three isolates of T. harzianum. Sequence analysis of the ITS 1 and 2 of rDNA has been especially reliable for the characterization of Trichoderma to the species level (Samuels et al., 2002). There is an on-line method for the quick molecular identification of Hypocrea/Trichoderma at the genus, clade and species levels based on an oligonucleotide barcode: a diagnostic combination of several oligonucleotides (hallmarks) specifically allocated within the ITS1 and 2 sequences of rRNA repeat (Druzhinina et al., 2006). From the sequence alignment, little variations were observed between T. harzianum isolates and T. longibrachiatum isolates. However, these differed by only one nucleotide position, suggesting the presence of relatively little genetic variation, if the ITS region is indicative of the overall genome. However, it was not necessary to consider all this variability in the hallmark design since the T. harzianum specific areas showed only little variability. Therefore, only nine hallmark combinations were sufficient to distinguish $T$. harzianum from its closely related species (Druzhinina et al., 2005). ITS1 sequences of Trichoderma section longibrachiatum are visually distinguishable by the consistently increased length of the fragment due to the non-homologous "insertion" of several TC repeats in the central part of the locus. Four isolates belonged to the duplet of species $T$. longibrachiatum/H. orientalis, which exhibits identical ITS1 and ITS2 sequences and cannot be differentiated further by TrichOKey. ITS sequence analysis is a reliable method for phylogenetic analysis and species identification within the section longibrachiatum of the genus Trichoderma (Kredics et al., 2003). 
In conclusion, all isolates were pre-screened by MP-PCR before ITS sequence analysis, which was reliably used for phylogenetic studies in Trichoderma. MP-PCR and ITS sequence analysis are reliable methods for species identification within the section longibrachiatum and harzianum of the genus Trichoderma.

\section{ACKNOWLEDGMENTS}

Research project (MIC 499) support was provided by grant from the Incubating Graduate Project Program for I. Almohimeed, undergraduate student in Botany and Microbiology Department, College of Science, King Saud University. Also, this study was partially funded by the Center of Excellence in Biotechnology Research, King Saud University.

\section{REFERENCES}

Abd-Elsalam KA, Asran-Amal A and El-Samawaty A (2007). Isolation of high-quality DNA from cotton and its fungal pathogens. J. Plant Dis. Prot. 114: 113-116.

Asran-Amal A, Abd-Elsalam KA, Omar MR and Aly AA (2005). Antagonistic potential of Trichoderma spp. against Rhizoctonia solani and use of M13 minisatellite-primed PCR to evaluate of the antagonist genetic variation. J. Plant Dis. Prot. 112: 550-561.

Chaverri P, Castlebury LA, Overton BE and Samuels GJ (2003). Hypocrea/Trichoderma: species with conidiophore elongations and green conidia. Mycologia 95: 1100-1140.

Druzhinina I and Kubicek CP (2005). Species concepts and biodiversity in Trichoderma and Hypocrea: from aggregate species to species clusters? J. Zhejiang. Univ. Sci. B 6: 100-112.

Druzhinina IS, Kopchinskiy AG, Komon M, Bissett J, et al. (2005). An oligonucleotide barcode for species identification in Trichoderma and Hypocrea. Fungal Genet. Biol. 42: 813-828.

Druzhinina IS, Kopchinskiy AG, Komon M and Kubicek CP (2006). An oligonucleotide barcode for species identification in Trichoderma and Hypocrea. Proceedings of the 8th International Mycological Congress, 21-25 August, 2006. Queensland, Australia, 1630-1700 IS2-0357.

Howell CR (2003). Mechanisms employed by Trichoderma species in the biological control of plant diseases: the history and evolution of current concepts. Plant Dis. 87: 4-10.

Kredics L, Antal Z, Doczi I, Manczinger L, et al. (2003). Clinical importance of the genus Trichoderma. A review. Acta Microbiol. Immunol. Hung. 50: 105-117.

Kullnig-Gradinger CM, Szakacs G and Kubicek CP (2002). Phylogeny and evolution of the genus Trichoderma: a multigene approach. Mycol. Res. 106: 757-767.

Nagy E, Kredics L, Antal Z and Papp T (2004). Molecular diagnosis, epidemiology and taxonomy of emerging medically important filamentous fungi. Rev. Med. Microbiol. 15: 153-162.

Rifai M (1969). A revision of the genus Trichoderma. Mycol. Pap. 116: 1-56.

Sambrook JE, Fritsch F and Maniatis T (2001). Molecular Cloning: a Laboratory Manual. 3rd edn. Cold Spring Harbor Laboratory Press, Cold Spring Harbor.

Samuels GJ, Dodd SL, Gams W, Castlebury LA, et al. (2002). Trichoderma species associated with the green mold epidemic of commercially grown Agaricus bisporus. Mycologia 94: 146-170.

Sariah M, Choo CW, Zakaria H and Norihan MS (2005). Quantification and characterisation of Trichoderma spp. from different ecosystems. Mycopathologia 159: 113-117.

Sieburg HB (1990). Physiological studies in silico. Stud. Sci. Complexity 12: 321-342.

White TJ, Burns T, Lee S and Taylor J (1990). Amplication and Direct Sequencing of Fungal Ribosomal RNA Genes for Phylogenetics. In: PCR Protocols: A Guide to Methods and Applications (Innis MA, Gelfand DH, Sninsky JJ and White TJ, eds.). Academic Press, San Diego, 315-322. 